\title{
Source Apportionment of Volatile Organic Compounds in SIDCO Kurichi Area Using Positive Matrix Factorization
}

\author{
Sangeetha $\mathbf{A}^{1}$, Jamuna $\mathbf{M}^{2}$ \\ ${ }^{1}$ M.E. Scholar, Environmental Engineering, Kumaraguru College of Technology, Coimbatore, TamilNadu, India \\ ${ }^{2}$ Assistant Professor, Department of Civil Engineering, Kumaraguru College of Technology, Coimbatore, \\ TamilNadu, India
}

\begin{abstract}
Air pollution is one of the inevitable problems in our environment. India experiencing these problems due rapid industrialization, urban development and increase in vehicles. It is important to investigate the pollutants that causing problems. There are various pollutants such as particulate matter, volatile organic compounds, ozone, $\mathrm{NO}_{\mathrm{x}}$ and $\mathrm{SO}_{\mathrm{x}}$ etc. Various experimental methods are available for measuring the concentration of various pollutants and to that monitoring station with sensors are available in major cities of India to measure the daily ambient air quality. The air quality modelling helps us to predict the ambient air quality in future and also comparison of source emission has been made easy. This work carries out the measurement of ambient air VOC at SIDCO industrial cluster of Kurichi area, Coimbatore. It is an important place to be noted for air pollution studies in Coimbatore because it has 286 industries and located in NH209. This project mainly focuses on the Volatile organic compound emission. The percentage of toluene contribution is $98.7 \%$ in oil blending. Toluene is emitted in larger amount compared to all other species. Though VOC is considered as an indoor air pollution it is important to control the VOC. The source contribution of VOC by various industries is found out using by Positive Matrix Factorization model, it is also used to find out the source apportionment of various air pollutant.
\end{abstract}

Keywords: Positive Matrix Factorization, VOC, CEPI, Factors, Species

\section{Introduction}

Atmospheric volatile organic compounds (VOCs) play an important role in determining the air quality and climate change. VOC causes various health effects to humans that includes eye, nose, throat irritation, headaches, loss of coordination, nausea, damage to liver, kidney and central nervous system. Some of the VOC causes cancer in humans and in animals. The anthropogenic sources of VOCs are industrial solvents, motor vehicles which uses gasoline and diesel, natural gases, biomass burning etc. The VOC reacts with ground level ozone and causes major effects. VOC in larger amount produce particulate matter, which in turn makes the environment worse. There are different VOC species present some of them are non-methane VOCs, aliphatic and aromatic hydrocarbons, alcohols, aldehydes, ketones, esters, and halogenated compounds benzene, toluene, xylene, m-p xylene, eth-benzene etc. India holds the second place in Asia in the VOC emissions. In India, the major anthropogenic sources of VOCs 
are residential combustion (41\%), on-road transportation (37\%), and industrial non-combustion (13\%). The studies on VOCs in India are limited even though there is increase in population, vehicular usage and industrialization. Some of those important studies have been conducted in the recent past mostly in metro cities such as in Delhi, the capital city of India, in Mumbai, a metro city and financial capital of India situated in western India, in Kolkata, a metro city in eastern India, in Hyderabad, a metro city in southern India in Agra in northern India, in Firozabad in northern India, in Mohali, a suburban site in north-western India etc. In India there is no legislation of VOC as a whole except national ambient air quality standard for Benzene by Central Pollution Control Board of India. Globally US Occupational Safety and Health Administration (OSHA) and World Health Organization (WHO) have proposed some guidelines and recommendations for VOCs.

\section{Methods and Materials}

\subsection{Study Area}

The area of Coimbatore city is 7469 sq.km and lies in the western part of Tamil Nadu. In Coimbatore, Kurichi is located at $10^{\circ} 55^{\prime} 11^{\prime \prime} \mathrm{N}$ latitude and $76^{\circ} 57^{\prime} 35^{\prime \prime}$ E longitude having industrial cluster for an area of about 180acres. It has two industrial estates and housing units constructed by Tamil Nadu Housing Board. The population of Kurichi village is 123,667 as per 2011. It has 9 hospitals, 3 educational institutions and 6 government primary schools surrounding SIDCO. About 286 industries are in operation, mainly engineering industries and few foundries.

\subsection{Data Collection}

SIDCO industrial cluster has a National Ambient Air Quality Monitoring station from which the concentration of 5 species of VOC like Benzene, Toluene, Xylene, m,p-xylene, eth-benzene are collected for the study period (01/07/2019 - 16/10/2019). The statistical interpretation of collected data was done and the minimum, maximum and average concentration of each VOC species in given in Table 1.

Table 1 Trend of VOC Species Observed at SIDCO, Kurichi

\begin{tabular}{|c|c|c|c|c|c|}
\hline & Benzene & Toluene & Xylene & m,pxylene & ethbenzene \\
\hline Maximum & 0.09 & 0.78 & 0.747 & 0.14 & 0.154 \\
\hline Minimum & 0.01 & 0.01 & 0.015 & 0.01 & 0.01 \\
\hline Average & 0.023 & 0.13 & 0.106 & 0.065 & 0.048 \\
\hline
\end{tabular}

\subsection{Model Simulation}

PMF uses speciated sample data based on the factorization method. It is a multivariate factor analysis tool which converts the sample data to matrices which means into factor contributions $(\mathrm{G})$ and factor profiles (F). To identify the source types, the details of factor profiles were to be collected also the 
information of measured source profile, emissions or discharge inventories were used. For best results EPA PMF requires multiple iterations. The minimum $Q$ value indicates the best solution.

In PMF model, any data matrix X ( $\mathrm{x} \times \mathrm{m}$ ) can be factorized into two matrices $\mathrm{G}(\mathrm{n} \times \mathrm{p})$ and $\mathrm{F}(\mathrm{p} \times$ $\mathrm{m}$ ); the residual matrix $\mathrm{E}$ as described in Equation (1), which also explains the case for source apportionment of atmospheric pollutants.

$$
\mathrm{X}=\mathrm{G} . \mathrm{F}+\mathrm{E} \text { or } \mathrm{x}_{\mathrm{i}, \mathrm{j}}=\quad \square, ., \quad+\square,
$$

where $n$ - number of samples, $m$ - number of species, $p$-number of factors $x_{i, j}$ - concentration of species $\mathrm{j}$ measured in sample $\mathrm{i}, \mathrm{p}$ - number of the factors contributing to the samples, $\mathrm{g}_{\mathrm{i}, \mathrm{k}}$ - relative contribution of factor $\mathrm{k}$ to sample $\mathrm{i}, \mathrm{f}_{\mathrm{k}, \mathrm{j}}$ - concentration of species $\mathrm{j}$ in factor profile $\mathrm{k}$, and $\mathrm{e}_{\mathrm{i}, \mathrm{j}}$, - error of PMF model for species $j$ measured in sample $i$. The aim is to find $g_{i, j} f_{k, j}$, and $p$ values that best reproduce the observations $x_{i}, j$. In calculation the values of $g_{i, k}$ and $f_{k, j}$ are adjusted till a minimum value of the objective function $\mathrm{Q}$ for a given $\mathrm{p}$ is found, where $\mathrm{Q}$ is defined in Equation (2)

$$
\square=\sum \quad \sum \quad
$$

Where $s_{i}, j$ is the uncertainty of the concentration of species $j$ in sample $i, n$ is the number of samples and $\mathrm{m}$ the number of species.

The aim of PMF run is to determine the number of factors, where factor indicates the sources of emission. The factors from PMF run have to be associated with with emission sources which is characterized by related chemical compositions. As the number of factors increases the error of estimated concentration decreases. But as the number of factors increases it is difficult to associate each factor with the corresponding proper source. In order to keep the number of factors as less as possible, multiple-indicator approach is developed ased on the values of the following three different statistical indicators for PMF model;

i. A single VOC's correlation coefficients between observed and modelled concentrations. ii. Overall correlation coefficients of all VOC's in PMF runs.

iii. The normalized ansolute error between the observed and modelledd concentration for the entire VOC dataset.

The factor and run is set up by using Mean Absolute Error (MAE) for the model. MAE includes comparison of observed vs predicted values.

$$
\sum|\square-\square|
$$

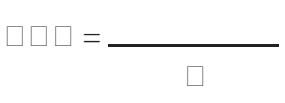

\subsubsection{Factor Selection}

The factor to run the model is found from MAE. The trails of factor (2,3 and 4) were used to find out the best fit of factor for the model. Factor should be greater than 1 so it cannot be used. The trails had been done upto $4^{\text {th }}$ factor because the MAE for $4^{\text {th }}$ factor is zero, which indicates the best fit. That is in that factor the actual and predicted values of $\mathrm{Q}$ becomes equal. From figure 1 it shows that $4^{\text {th }}$ factor is best fit as the MAE is zero. If the MAE is not equal to zero, then greater number of trails have to be done. 


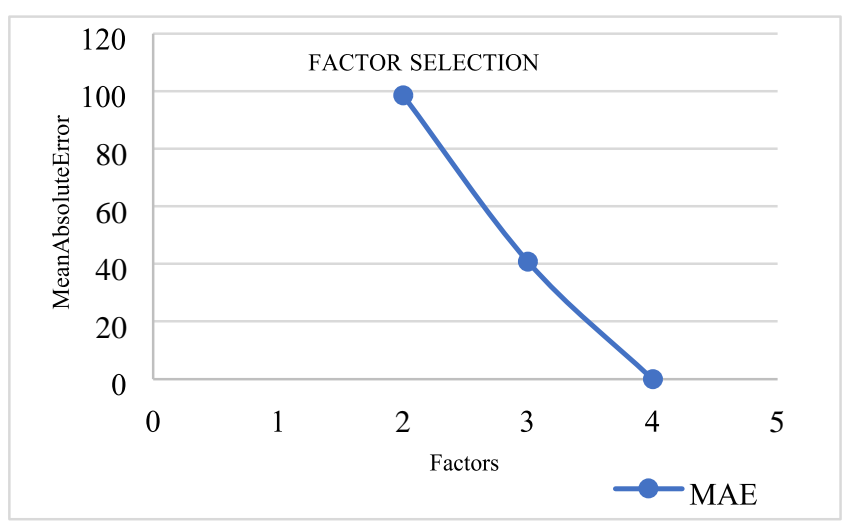

Fig. 1. Factor Selection of PMF Model

\subsubsection{Run Selection}

The number of runs indicates that the model is to be analyzed for the number of times. For number of runs the trial were made by fixing the runs for $5,10,20,50,75$, as these runs show that there was greater difference in MAE value. From figure 2 it was found that runs between 10 to 20 show minimum MAE and the curve is $\mathrm{V}$-shaped. The curve increases from run 5 and decreases at run 13 and again increases from run 20, so that the run 13 is selected for the best fit of the model

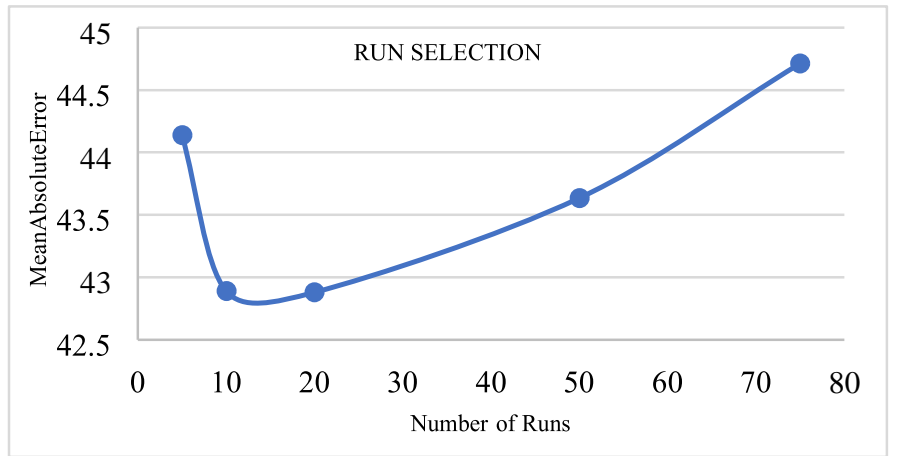

Fig. 2. Run Selection of PMF Model

\section{Results and Discussion}

\subsection{Source Identification by PMF}

The profiles of the factors resulting from the $4^{\text {th }}$ factor solution is shown in figure 3 . The source profile of different sources of VOC's in given in semi-log graph. It shows the concentration of each species and the percentage of each species. The following four factors have been identified as the sources of VOC; 


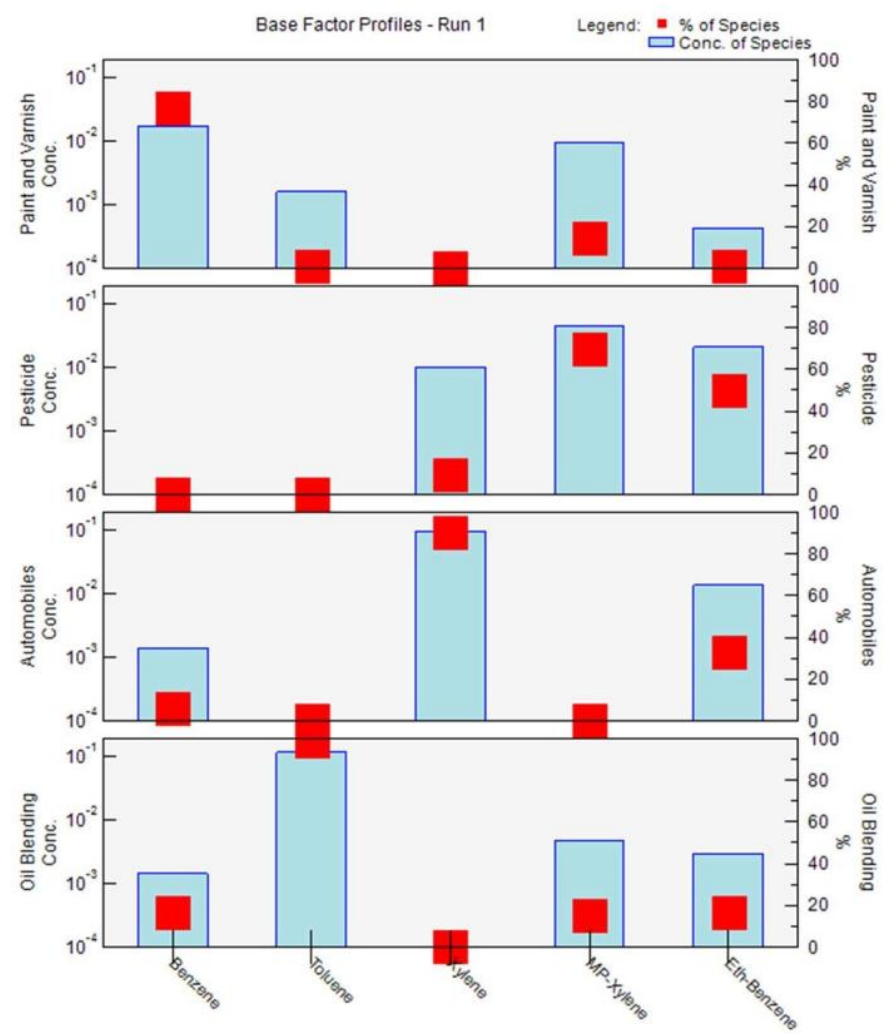

Fig. 3. Source Profile of Different Sources of VOC

i. Paints and Varnish

The emission from paints and varnish industry depends on the handling of dry pigments, type of solvent used and the mixing temperatures. The factor contribution of Benzene is $0.01745(77.0 \%)$, Toluene is $0.00162(1.2 \%), \mathrm{m}, \mathrm{p}-$ Xylene is $0.00956(14.6 \%)$ and EthBenzene is $0.00042(1.0 \%)$. Benzene involves is the highest rate of emission in paints and varnish industry. ii. Pesticide Formulation

The pesticide formulation can emit some of the VOC compounds such as Toluene, MPXylene, Benzene and Eth-Benzene. Factor contribution of Benzene is $0.00004(0.2 \%)$, Xylene is 0.01028 (9.5\%), m,p-Xylene is 0.04589 (70.1\%) and eth-Benzene is 0.02083 (49.7\%). Among the emission from pesticide formulation $\mathrm{m}, \mathrm{p}$ - Xylene and eth-Benzene has the highest contribution. iii. Automobiles

The emission from automobiles include xylene, ethyl benzene, benzene, aldehydes, and their methyl-derivatives and heterocyclic compounds of nitrogen, oxygen and Sulphur. The vehicles that use diesel as their fuel falls under this category. The factor profile is characterized by contribution of Benzene at 0.00137 (6.1\%), Xylene at $0.09783(90.1 \%)$ and Eth-Benzene at 0.01377 (32.9\%). These profiles show that the Xylene makes the major contribution in the automobile emission. 


\section{iv. Oil Blending}

The process of blending low grade crude oil with the high grade to increase the sale price. VOC's emitted from oil blending process includes Benzene, Toluene, m,p-Xylene and EthBenzene. The factor contribution of Benzene is 0.00137 (16.8\%), Toluene is 0.12856 (98.7\%), Xylene at $0.00045(0.4 \%)$, MP-Xylene is $0.01006(15.4 \%)$ and Eth-Benzene is $0.00689(16.4 \%)$. From these results toluene has the highest contribution.

\subsection{Factor fingerprints}

The factor fingerprints shown in figure 4 shows the VOC composition patterns of the four industries. Paint and varnish industries shows the emission of Benzene, Toluene, MP-Xylene and Eth-Benzene. Among these Benzene is emitted at a range of $78 \%$ from paint and varnish alone. Oil blending industry emits Toluene to $100 \%$ so it must be focused to reduce and control the emission. And next major industry that plays in the emission of Benzene, toluene, MPXylene and Eth-Benzene is paint and varnish industry, automobiles and pesticide. Automobile emission is from the transportation of vehicles in that area.

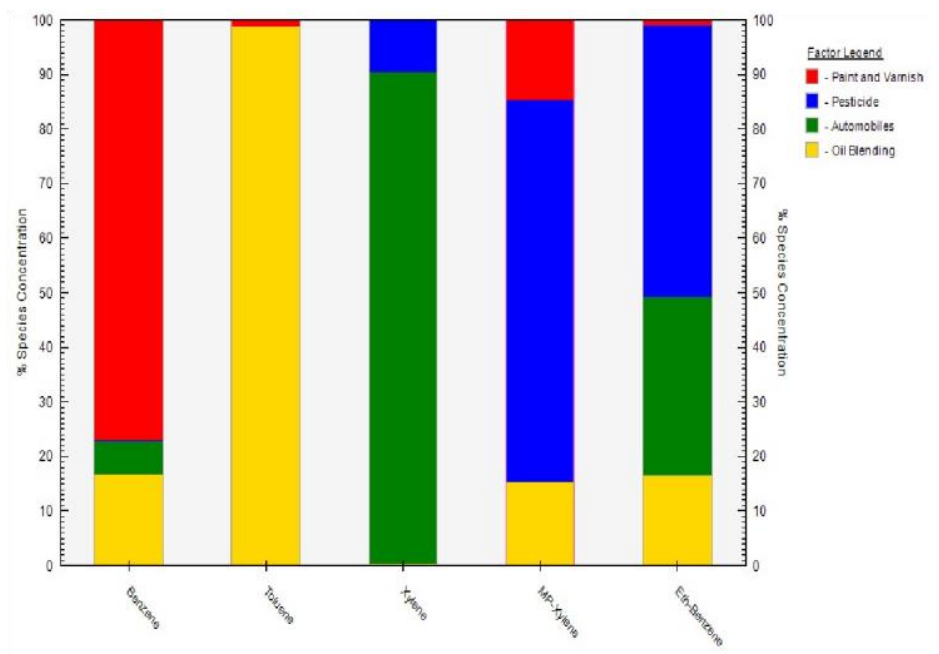

Fig. 4. VOC Composition Patterns of Four Industries

\section{Conclusion}

Four VOC emission sources were extracted via PMF simulations from the dataset comprising of 5 VOC species measured online at Indoshell Mould Ltd at urban site in SIDCO, Kurichi Coimbatore from July to October of 2019. This method assumes that four emissions sources, paint and varnish, pesticide, automobiles and oil blending are responsible for VOCs concentrations at the ground site. PMF extracted four factors from the SIDCO VOCs data set. The PMF model fitted the monitored data set very well with four factors and generated source profiles. The four factors were shown to be strongly influenced by oil blending process as well as by the VOCs sources. Our results show that oil blending plays an important role in the results of PMF analyses. Variations in oil blending processing and varying of contributions from VOCs sources both lead to changes in concentrations and compositions of VOCs in the atmosphere. 
VOC composition for paint and varnish, the contribution of benzene is $77.0 \%$, followed by toluene $(1.2 \%)$, m,p - Xylene (14.6\%) and Eth-Benzene $(1.0 \%)$. The percentage of toluene contribution is $98.7 \%$ in oil blending and $1.2 \%$ in paint and varnish. Toluene is emitted in larger amount compared to all other species. The VOC composition of automobiles, the contribution of Benzene is $6.1 \%$, Xylene (90.1\%) and Eth-Benzene $(32.9 \%)$ and for pesticide, contribution of Benzene is $0.2 \%$, Xylene (9.5\%), MP-Xylene (70.1\%) and Eth-Benzene (49.7\%). From this study it is revealed that the SIDCO industrial cluster has the VOC emission and the control measures of VOC emission should be taken. The emission of Toluene prevails more so it should be concentrated. The future emission can be prevented and reduced by various control measures.

The Future work can be carried out by manual VOC collection from the study area for different seasonal and temporal variations. And the PMF results can be compared with CMB and Unmix models for better interpretation.

\section{Acknowledgment}

The authors are grateful to the management of Kumaraguru College of technology, Coimbatore, India, for the facilities made available for this study. Thanks to our family and friends for their support. Thanks to all the residents and shop owners of the study area for their support.

\section{References}

[1] Adam Reff, Shelly I. Eberly(2012), 'Receptor Modeling of Ambient Particulate Matter Data Using Positive Matrix Factorization: Review of Existing Methods', Journal of the Air \& Waste Management Association, Vol.57, pp.146-154.

[2] Aravind.T.P.A, Mohammed Haneef.M.V (2016), 'Monitoring, Analysis and Modelling of Ambient Air Quality Status at Indoshell Mould Ltd., Sidco, Coimbatore using Artificial Neural Network', IJSRSET1622399, Vol.2, No.2, pp.1172-1175.

[3] Bin Yuan, Min Shao et al., (2012), 'Volatile Organic Compounds (VOC's) in urban air: How chemistry affects the interpretation of positive matrix factorization (PMF) analysis', Journal of Geophysical Rearch, Vol.117.

[4] Dash.A.K, Sahu.S.K et.al., (2017), 'Air Dispersion Model to Study the Point Source Air Pollution and its Impact on Ambient Air Quality', Asian Journal of Chemistry, Vol.29, No.5.

[5] Dordevic Dragana, Petrovic Srdan (2013), 'Applying receptor models Unmix and PMF on real data set of elements in PM for sources evaluation'.

[6] Ethirajan.R and Mohan.S (2012), 'Comparitive evaluation of VOC Source Profiles Developed by PMF and Unmix Models', International Journal of Environmental Science and Development, Vol.3, No.5.

[7] Indrani Gupta, Abhaysinh Salunkhe (2012), 'Source Apportionment of $\mathrm{PM}_{10}$ by Positive Matrix Factorization in Urban Area of Mumbai, India', The Scientific World Journal, Vol.2012, pp.1-13. 
[8] Junyu Zheng, Yufan Yu et.al., (2013), 'Industrial sector-based volatile organic Compound (VOC) Source Profiles Measured in Manufacturing Facilities in the Pearl River Delta, China', Science of the Total Environment, Vol.457, pp.127-136.

[9] Kurtis G . paterson, Jessica L . sagady et.al., (1999), 'Analysis of Air Quality Data Using Positive Matrix Factorization', Environmental Science and Technology, Vol.33, pp.635641.

[10] Mohammed Siraj Ansari, Sharpudin.J (2013), 'Assessment of Ambient Air Quality in SIDCO Industrial Cluster - Coimbatore', International Journal for Research in Emerging Science And Technology, Vol.1, No.7.

[11] Pallavi, Baerbel Sinha et al,. (2019), 'Source apportionment of Volatile Organic Compounds in the North-West Indo Gangetic plain using Positive Matrix Factorization model', Atmospheric Chemistry and Physics, Vol.343.

[12] Selvakumar Madhavan, T.Meenambal (2009), 'Multiple linear regression analysis for air pollutant concentrations in Coimbatore city', Environmental Science, Vol.4, No.6,pp. 458461.

[13] Yung - Chang Su, Wei - Hao Chen et al,. (2019), 'Source apportionment of Volatile Organic Compounds (VOC's) by Positive Matrix Factorization (PMF) supported by model simulation and source makers - using petrochemical emissions as a showcase', Environmental Pollution, Vol.254

[14] http://www.integrated-assessment.eu/eu/node/208.html

[15] https://air quality.com/place/india/coimbatore/93c43db7?lang=en\&standard=aqi us

[16] https://app.cpcbccr.com/AQI_India/

[1] https://www.epa.gov/air-research/positive-matrix-factorization-model-environmentaldataanalyses 